Cad. Benjaminianos, Belo Horizonte, v. 13, n. 2, p. 229-242, 2017

\title{
"Mademoiselle Bistouri": diálogos com a modernidade
}

\section{"Mademoiselle Bistouri": dialogues with modernity}

\author{
Fabiana Fanganiello \\ Universidade Federal de São Paulo (Unifesp), São Paulo, São Paulo / Brasil \\ fabilivros@uol.com.br
}

Resumo: "Mademoiselle Bistouri" (Senhorita Bisturi), um dos poemas que integram o volume Pequenos poemas em prosa, de Charles Baudelaire, apresenta, tanto no plano do conteúdo quanto no da expressão, duplicidades de sentido amplamente exploradas pelo poeta francês. Além disso, esse poema aborda questões fundamentais do período moderno, como os avanços tecnológico-científicos e a experiência do homem no início do desenvolvimento das metrópoles. Com base nessas perspectivas, é objetivo deste artigo estudar o poema "Mademoiselle Bistouri" à luz das propostas teóricas do próprio Baudelaire, de Benjamin e de Freud, focalizando certos temas da modernidade, tais como a loucura, a flânerie e o próprio fazer poético.

Palavras-chave: poesia em prosa; Charles Baudelaire; loucura; flânerie; modernidade.

Abstract: "Mademoiselle Bistouri ", one of the poems that is part of Charles Baudelaire's Small Poems in Prose volume, presents both the content and the expression of the duplicities of meaning widely explored by the French poet. In addition, this text deals with fundamental issues of the modern period, such as technological and scientific advances and the experience of man at the beginning of the development of metropolises. Based on these perspectives, it is the objective of this article to study the poem "Mademoiselle Bistouri" in the light of Baudelaire, Benjamin and Freud's own theoretical proposals, focusing on certain themes of modernity, such as madness, flanerie and poetic making itself.

Keywords: poetry in prose; Charles Baudelaire; madness; flanerie; modernity. 


\section{Introdução}

"Mademoiselle Bistouri" (Senhorita Bisturi) é um dos últimos poemas dos Petits poèmes en prose (Pequenos poemas em prosa), ${ }^{1}$ volume formado pelos textos que Baudelaire fez publicar em jornais franceses a partir de 1857. Nessa época, o poeta francês começava a ter visibilidade no meio literário, sobretudo em razão da força e da importância do seu livro mais conhecido, Les Fleurs du Mal (Flores do Mal).

Sua poesia em prosa versa sobre algumas questões que se tornaram fundamentais para o desenvolvimento da arte e da literatura a partir do século XIX. Dentre essas, podemos citar o impacto das mudanças sociais e econômicas causadas pelos avanços tecnológico-científicos, a experiência humana nas metrópoles em franca expansão e, especialmente, o papel da arte e da literatura em um mundo em que os homens têm suas perspectivas alteradas pela fotografia, pelo jornal e pelos meios de transporte que transformaram a forma de viver e de se relacionar em sociedade.

Sob a égide de todas essas mudanças, Baudelaire não passou imune ao questionamento do papel da poesia num momento em que o público já não se reconhecia na literatura inspirada nos autores clássicos que os poetas se propunham a oferecer, questão que Benjamin (1989, p. 103-104) também observou:

Que seja assim que, em outras palavras, as condições de receptividade da poesia lírica se tenham tornado mais desfavoráveis, é demonstrado por três fatos, entre outros. Primeiro, porque o lírico deixou de ser considerado como poeta em si. Não é mais "o aedo", como Lamartine ainda o fora (...). Segundo, depois de Baudelaire, nunca mais houve um êxito em massa da poesia lírica. (...) Uma terceira circunstância, decorrente das duas primeiras: o público se tornara mais esquivo mesmo em relação à poesia lírica que lhe fora transmitida no passado.

Além de apontar para essa "perda de auréola" da poesia no contexto da modernidade, em Baudelaire também encontramos um diálogo crítico com a inevitabilidade das pequenas revoluções do saber

\footnotetext{
${ }^{1}$ Para este trabalho, escolhemos a edição bilíngue dos Pequenos poemas em prosa da Editora Record, publicada em 2009, com tradução de Gilson Maurity. Nas referências ao título e nas citações de trechos do poema mantivemos o original francês, com respectiva tradução nas notas de rodapé.
} 
humano que começaram no século XIX e, desde então, não cessaram mais. Assim, nos seus poemas em prosa, essa modernidade é observada pelo olhar irônico e, ao mesmo tempo, ambíguo, de figuras que desfilam, solitárias e ignoradas, por essa cidade moderna, inóspita e cruel.

É nesse contexto que se encontra a personagem do poema que desejamos analisar neste artigo. "Mademoiselle Bistouri" trata de uma mulher - possivelmente, uma prostituta - que surpreende um homem na rua, quando já é noite, insistindo na ideia de que ele é um médico. Curioso com a estranha insistência da mulher, o homem, narrador da cena, aceita o convite para ir até a casa dela e a acompanha até um casebre pobre, localizado em alguma parte distante da cidade. Ao longo da conversa, os dois estabelecem uma relação cada vez mais próxima, momento em que a mulher revela possuir uma obsessão por médicos, citando nomes de alguns e apresentando-lhe uma coleção de retratos de médicos famosos, com os quais ela sugere ter tido alguma relação de ordem íntima no passado. Com o estabelecimento de certa confiança entre os dois, a mulher lhe confessa que seu desejo é ser visitada por um médico cujo jaleco esteja manchado de sangue. Diante de algo tão bizarro, o narrador procura descobrir a origem do comportamento de sua interlocutora, mas ambos permanecem sem resposta, pois ela lhe afirma que não sabe quando tais vontades começaram.

Podemos identificar no exposto acima que o poema aponta para questões centrais da modernidade, o que torna urgente uma leitura a partir dessa perspectiva, como contribuição para as pesquisas acerca da obra do poeta francês. Assim, trataremos, especificamente, de três pontos, loucura, flânerie e fazer poético, ligados a debates sobre a modernidade em arte e literatura, a partir das discussões teóricas propostas, respectivamente, por Freud (2017), Benjamin (1989) e o próprio Baudelaire (1992).

\section{A Modernidade sob o olhar de Baudelaire}

\subsection{La prostitueé ou la folle? (A prostituta ou a louca?)}

O poema causa estranhamento desde o título - "Mademoiselle Bistouri" -, no qual podemos observar, de imediato, o paroxismo que Berardinelli (2007) identifica na obra de Baudelaire. A imagem, responsável pelas primeiras hipóteses acerca do teor do texto, alia duas ideias opostas: o frescor e a beleza da "mademoiselle" se unem à perspectiva da dor e 
da violência sugerida pelo nome "bistouri". Com isso, certo conteúdo é antecipado por esse título, posto que não se trata de qualquer objeto cortante, nem de um instrumento de uso comum. Refere-se, a saber, a uma determinada atividade profissional, remetendo-nos à figura de um médico, ou de um cirurgião, a qual, como veremos, é parte central da fantasia elaborada pela mulher. Devido a essa natureza paradoxal, a expectativa de um conteúdo que oferecesse um perfil ou um retrato feminino, implícito no emprego do termo "mademoiselle", é esvaziada antes mesmo de o leitor conhecer a mulher a que o título faz referência.

Ao longo da leitura, aliás, somos levados a perceber que não estamos diante de uma personagem feminina como o significado de "mademoiselle" poderia fazer supor. A suspeita causada pelo nome que lhe foi dado vai gradativamente confirmando-se, a começar pelo fato de que ela não é uma mulher tão jovem, como a própria personagem afirma ao narrador: "Après tout, je suis assez belle femme, quioque pas trop jeune" (p. 262). ${ }^{2}$

Após o convite, aceito não sem relutância e sem ironia pelo narrador ("Sans doute, j'irai vous voir, mais plus tard, après le médicin, que diable!", p. 256), ${ }^{3}$ a primeira impressão faz pensar que a mulher é uma prostituée, hipótese que se fortalece se considerarmos o cenário onde os interlocutores se encontram. Tanto "l'extrémité du faubourg" ("o fim do bairro") como "sous les éclairs du gaz" ("sob os clarões do gás", p. 256) funcionam como uma espécie de moldura para essa primeira cena e sugerem a ocasião e o espaço citadino típicos da atividade da prostituição. Por outro lado, nos parágrafos finais do texto, essa imagem da prostituta é relativizada, na medida em que ela estabelece uma relação ambígua com os homens que a visitam, como lemos no trecho que segue:

- Dame! Come je les ai dérangés inutilement, je laisse dix francs sur la cheminé. - C'est si bon et si doux, ces hommes-là ! - J'ai découvert à la Pitié un petit interne, que est joli comme un ange, et qui est poli ! et que travaille, le pauvre garçon! Ses camarades m'ont dit qu'il n'avait pas le sou, parce que ses parents sont des pauvres que ne peuvent rien lui envoyer (p. 262) ${ }^{4}$.

\footnotetext{
${ }^{2}$ Além disso, eu sou uma bela mulher ainda, conquanto não muito jovem (p. 263).

${ }^{3}$ Sem dúvida, eu irei vê-la, mais tarde, depois do médico, que diabo! (p. 257; grifo do autor).

${ }^{4}$ Ora essa! Como eu os ocupei inutilmente, deixo-lhes uma nota de 10 francos sobre a lareira. São tão bons e tão doces estes homens. Descobri na Santa Casa um pequeno interno que é belo como um anjo, e bem-educado. E como trabalha o pobre menino! Seus
} 
À figura ambígua dessa mulher, confronta-se, entretanto, a da folle (louca), quando o narrador - e também o leitor - descobre que ela apresenta um comportamento estranho, confirmando a suspeita que se instaurou desde a observação do título do poema. A personagem é dominada por uma espécie de fetiche: ela manifesta, desde o início do diálogo, uma obsessão por médicos, o que, de certa forma, resgata os sentidos implicados na expressão "Mademoiselle Bistouri". Assim, a fragilidade, que se verifica no significado de "mademoiselle", aparece unida à presença do médico com jaleco manchado de sangue, como ela o deseja, imagem atualizada pelo substantivo "bistouri".

A aproximação desse universo de "bizarreries" vivida pelo narrador deve muito ao emprego do discurso direto na composição do texto. A oralidade por via da qual as personagens se desvelam faz com que acompanhemos a conversa íntima que se desenvolve no correr da narrativa. Ao tornarem-se interlocutores, é inevitável que se estabeleça uma relação menos distante entre ambos, o que fica perceptível na substituição do pronome "vous" pelo "tu" depois que os dois já se encontram dentro da casa dela. No início do texto, ela o trata com formalidade: "Vous êtes médicin, monsieur?", p. 256. Já nas dependências do casebre, os dois abandonam o tom formal, criando um ambiente de franca cumplicidade, como vemos no trecho:

- Mais, lui dis-je, suivant à mon tour, moi aussi, mon idée fixe pourquoi me crois-tu médecin?

- C'est que tu es si gentil et si bon pour les femmes (p. 260). ${ }^{5}$

Além do estabelecimento dessa intimidade, é preciso reconhecer também que o emprego do discurso direto põe em evidência um forte tom prosaico, o que pode ser entendido como uma estratégia a partir da qual Baudelaire persegue "le miracle d'une prose poétique, musicale, sans rythme et sans rime" (p.16), ${ }^{6}$ como ele mesmo escreveu na carta endereçada a Arsène Houssaye, utilizada, pelos editores póstumos,

colegas disseram-me que ele não tem um tostão, porque seus pais são pobres e nada the podem dar (p. 263).

5 "Mas", disse-lhe eu, seguindo também minha ideia fixa, "por que me crês médico?". "É que és tão gentil e tão bom para as mulheres" (p. 261).

6 "o milagre da prosa poética, musical, sem ritmo e sem rima" (p. 17). 
como introdução aos "Pequenos poemas em prosa". A escolha pelo registro informal, que só se realiza no ambiente privado dos quartos de dormir, também contribui para o exercício da liberdade discursiva das personagens, anulada, fora dali, pelo barulho da multidão e pelos ruídos da cidade grande.

Isso não impede, por outro lado, a presença de artifícios de linguagem que aproximam o texto de características mais alinhadas aos textos poéticos, como a elaboração de imagens antagônicas (PAZ, 2013), que apontamos quando discutimos o título do texto, e a exploração dos recursos de sonoridade. No caso de "Mademoiselle Bistouri", podemos citar a escolha vocabular e a presença de certa repetição na fala da mulher, que causa uma explícita perturbação no narrador, e a qual ele mesmo classifica como um refrão, voltando nossa atenção não apenas para o que é repetido, mas também, e sobretudo, para o próprio ato de repetir.

Quelques instants plus tard, me tutoyant, elle reprenait son antienne, et me disait : «Tu es médecin, n'est-ce pas, mon chat?»

Cet inintelligible refrain me fit sauter sur mes jambes. «Non!» criai-je furieux (p. 258). ${ }^{7}$

Nesse sentido, a repetição presente no discurso da mulher e o caráter estranho do seu comportamento podem ser entendidos, à luz das propostas da Psicanálise, como um recalque de um evento traumático vivenciado por ela, que poderia ser a origem da repetição de ideias e de termos (FREUD, 2017), especialmente quando se atenta para o fato de que o narrador nos revela que ela mesma declara não saber quando esses desejos começaram. Além disso, a mulher não percebe que se repete - seu vocabulário atualiza sempre a mesma ideia: cirurgião, interno, médico, sangue, cortar, etc.

Ainda considerando a perspectiva de uma leitura de fundo psicanalítico, a ótica do trauma pode auxiliar-nos na compreensão de dois outros pontos do poema, diretamente relacionados ao comportamento bizarro e ao fetiche da mademoiselle. Neles, aliás, implicam-se a mesma

\footnotetext{
${ }^{7}$ Alguns instantes mais tarde, tratando-me com intimidade, ela retomava sua cantilena. "Você é médico, não é, meu gato?".

Esse ininteligível refrão fez-me saltar sobre os calcanhares: "Não!" gritei furioso. (p.259).
} 
duplicidade de sentido que já identificamos no título e que está presente também na própria figura da personagem-título.

O primeiro ponto é a coleção de retratos de médicos que a personagem apresenta ao narrador durante a visita. As fotos renovam o desejo por médicos, tornando-o ininterruptamente presente, porém elas podem representar apenas ilusões, parte constituinte de um mundo de fantasia criado por ela. Não nos esqueçamos de que seu discurso vacila e que ela mesma não sabe precisar quando essa predileção por médicos, de fato, começou. Dessa forma, devido a essa condição, não é possível depositar plena confiança nas informações que ela oferece. Tomar o narrador por médico já não é uma ilusão criada por ela? As fotos podem não ser de ex-clientes, mas apenas um elemento que ela utiliza para dar coerência à sua fantasia e justificar o convite feito a um desconhecido que ela encontrou na rua.

O outro ponto que selecionamos é a mancha de sangue que deveria aparecer no jaleco do (suposto) médico quando ele viesse visitá-la, imagem que acentua, sem dúvida, o caráter bizarro do comportamento da personagem. O sangue traz em si mesmo a presença dupla da vida e da morte, na medida em que pode ser tanto uma referência àquela quanto a esta. Nesse sentido, o substantivo escolhido para lhe identificar - "bistouri" - estabelece um novo significado, em analogia com essa imagem do título, posto que bisturi pode representar vida (ao funcionar como instrumento que permite ao médico um procedimento cirúrgico que pode salvar uma vida), mas não deixa de ser também, paradoxalmente, o que pode levar à morte de alguém. Além disso, no que concerne à questão do trauma, a mancha de sangue desejada por ela pode remeter a um evento traumático que lhe é impossível confessar, como, por exemplo, a perda violenta da virgindade, a violência sexual, o aborto, ou mesmo um crime há muito tempo cometido.

\subsection{Narrador e Mademoiselle: dois flâneurs}

Ainda quanto ao discurso das personagens, é preciso observar que o processo narrativo só é instaurado quando o narrador cede ao desejo da desconhecida que o aborda, tornando possível a existência (e o compartilhamento) de duplicidades de sentido como as que tentamos apontar anteriormente. Esse expediente, a nosso ver, é marca da construção do poema baudelairiano, sobretudo quando observamos o conteúdo sobre qual versa o diálogo entre narrador e mademoiselle. Ambos são reféns de uma paixão que os domina: a dela, pela realização 
de seu insólito desejo; e a dele, pela resolução de mistérios típicos da cidade grande, razão pela qual ele dá sua concordância quando a mulher insiste para que ele a acompanhe.

Assim, o diálogo é estabelecido entre duas figuras que se encontram nos seus espaços mais característicos, o que nos obriga a destacar o tema da flanerie dentro do poema. Lembremos que, quando a mulher aborda o narrador, eles estão "à l'extrémité do faubourg, sous les éclairs du gaz" (p. 256), o que sugere a ideia de que os dois estavam flanando, tal qual o narrador do texto "Um homem da multidão", de Poe (2010). O conto de Poe trata de um flâneur que observa e acompanha um desconhecido, escolhido no meio da multidão, durante toda uma madrugada em suas andanças pela cidade grande. Mesma observação é a que se propõe o narrador do poema de Baudelaire quando aceita o convite da mulher. Se, como entende Benjamin (1989), o ato investigativo é traço do flâneur, o narrador de "Mademoiselle Bistouri" também pode ser identificado com um flâneur, no seu gosto pelo mistério e pelos enigmas da cidade moderna.

Para tal a flânerie oferece as melhores perspectivas. "O observador - diz Baudelaire - é um príncipe que, por toda a parte, faz uso do seu incógnito". Desse modo, se o flâneur se torna sem querer detetive, socialmente a transformação lhe assenta muito bem, pois justifica a sua ociosidade. Sua indolência é apenas aparente. Nela se esconde a vigilância de um observador que não perde de vista o malfeitor. Assim, o detetive vê abrirem-se à sua auto-estima vastos domínios. Desenvolve formas de reagir convenientes ao ritmo da cidade (p. 38).

A multidão possui também um caráter duplo que se faz presente na história da prostituta louca que capta a atenção do irônico flâneur de Baudelaire. Se essa multidão impõe a massificação que Benjamin (1989) denunciou, quando escreve que a multidão "não é apenas o mais novo refúgio do proscrito; é também o mais novo entorpecente do abandonado. O flâneur é um abandonado na multidão. Com isso, partilha a situação da mercadoria" (p. 51), num sentido contrário, serve também de abrigo aos que não podem, por diversas razões, viver de forma inclusiva com este mundo, a começar exatamente pelas duas personagens, figuras marginalizadas e vistas como párias no mundo burguês das metrópoles que começam a se agigantar. É por estar nessa posição que o narrador 
de Baudelaire consegue observar a cidade e as personagens que por ela perambulam, dando-lhes a visibilidade que lhes foi violentamente negada. Quando aceita dar escuta à mulher, o narrador, de alguma forma, reage a essa massificação e dá voz aos que jamais seriam ouvidos e aos que não possuem qualquer representatividade social.

As poucas referências descritivas que aparecem no texto "Mademoiselle Bistouri" permitem apontar o quanto esse isolamento social causou impacto na constituição da personagem. Além de "passear" desacompanhada, num momento do dia reservado às atividades da vida boêmia, vestida e maquiada para cumprir algum compromisso social, a mulher morava em um "taudis" (casebre). Essas marcas ressaltam a baixeza da sua posição social e a precariedade financeira a que estava submetida, fortalecendo a ideia da prostituição, sobretudo quando percebemos que, nesse espaço íntimo, não há referência a qualquer membro da sua família ou a outra pessoa que a pudesse acompanhar. Sua loucura, de certa forma, pode ser entendida como uma reação a essa condição. Sua busca por satisfação junto a homens desconhecidos pode ser entendida como uma maneira de lutar contra o também isolamento físico e espiritual imposto pelas novas prerrogativas de um progresso citadino que se fez em detrimento das relações humanas e da qualidade de vida da população. É novamente Benjamin (1989) quem nos explica a dimensão dessas mudanças na vida das grandes cidades:

A numeração dos imóveis na cidade grande fornece um ponto de referência adequado para avaliar o progresso da normatização. Desde 1805, a administração napoleônica a tornara obrigatória para Paris. Em bairros proletários, contudo, essa simples medida policial encontrou resistências (...). Naturalmente, tais residências não puderam, por muito tempo, contra o empenho de compensar, através de uma múltipla estrutura de registros, a perda de vestígios que acompanha o desaparecimento do ser humano nas massas das grandes cidades (p. 44).

Ao interromper a caminhada do narrador, a "Mademoiselle" busca para si uma visibilidade que se coloca como uma contundente manifestação contra os signos da modernidade que encaminharam o "homem da multidão" à nefasta anulação física e moral representada pela personagem. Baudelaire, por sua vez, soube incorporar esses signos ao seu poema, pois, em "Mademoiselle Bistouri", vemos, tematizados, 
o desenvolvimento da medicina, a reprodutibilidade das imagens fotográficas, a iluminação pública e a vida social nos espaços impactados pela presença de uma população que vê, indefesa, a transformação das suas vidas pelas novas formas de convívio e de relações de poder. No mais, é preciso observar que, se essas transformações atingem níveis relevantes em termos de progresso tecnológico, expulsam de seu horizonte o elemento humano e suas complexidades. Não é sem razão que Thélot (2014) afirma que a loucura da mulher é a « d'un monde moderne où médicine et photographie (...) ont pu s'emparer des corps comme des visages dans leurs opérations chirurgicales, comme dans leurs portraits reproductibles » (p. 222).

$\mathrm{O}$ contato entre a mulher e o narrador vislumbra, para ambos, a possibilidade de mudança de posição. Ela o classifica como médico e ele passa a sê-lo, pois, aceitando a alcunha e assumindo o papel que the foi destinado, abre-se espaço para outro olhar sobre o mundo e alterase a realidade subjetiva de cada um. Em outras palavras, o narrador é tocado pela "folie" da mulher ao lhe oferecer, no lugar de tratamentos - médicos ou não - violentos, a sua escuta. O mundo sem forma e sem sentido observado pelo flâneur, no qual só resta caminhar e observar, é invadido por outro que, a despeito de sua anormalidade, goza de lógica e de organização, servindo como uma para-realidade onde é possível viver (VAN ZUYLEN, 2004). Para a mulher, o convite é a oportunidade de ser ouvida, quando, fora do seu microcosmo, certamente seriam muitas e eficientes as formas de silenciamento a que seria submetida. Lembremos que ela o encontra na rua, ela não se dirigiu a um hospital talvez, justamente, porque ela mesma intuía que os médicos não poderiam ajudá-la (Il y en a qui me disent froidement: "Vous n'êtes pas malade du tout", p. 260). ${ }^{8}$

\subsection{Uma prece pela fantasia}

Do lado do narrador, esse contato com a fantasia da mulher pode revelar também, por parte dele, o desejo de ver o mundo sob um olhar diferente. Certamente, a fascinação que ela exerce vem do fato de que ele, dentro do mundo dela (cuja metáfora parece ser o casebre), pode experimentar outra realidade, ser o que não é. Assim, não é por um

\footnotetext{
${ }^{8}$ Alguns me dizem friamente: "Você não está doente" (p. 261).
} 
médico que ela procura exatamente, mas por alguém que represente um médico. Durante o diálogo, eles aceitam representar, imaginando uma fantasia da qual, no momento em que ele penetra no seu casebre, os dois fazem parte. Nesse sentido, caberia pensar se Baudelaire não estaria fazendo uma crítica acerca das visões de mundo que se opõem à presença da fantasia e da imaginação em sua concepção de realidade. Nesse sentido, a "mademoiselle" e o poeta flâneur se igualam, já que os dois criam histórias elaboradas por suas fantasias. Essa crítica fica mais perceptível se lemos um dos textos que Baudelaire (1992) escreveu sobre o Salon de 1859:

C'est l'imagination qui a enseigné à l'homme le sens moral de la couleur, du contour, du son et du parfum. Elle a créé, au commencement du monde, l'analogie et la métaphore. Elle décompose toute la création, et, avec, les matériaux amassés et disposés suivant des règles dont on ne peut trouver l'origine que dans le plus profond de l'âme, elle crée un monde nouveau, elle produit la sensation du neuf. Comme elle a créé le monde (on peut bien dire cela, je crois, même dans un sens religieux), il est juste qu'elle le gouverne (p. 258).

Não seria exatamente isso o que Mademoiselle Bistouri tem coragem de fazer e, rechaçada por um mundo hostil, busca manter a integridade da sua fantasia? Quanto ao comportamento dos dois, não poderíamos pensar que o refúgio na conversa íntima não seria uma forma de revoltar-se e dar às costas à pobreza criativa da modernidade, relativizando, por conseguinte, a ideia de normalidade? Van Zuylen (2004) chama a atenção para o fato de que na genuína reação da prostituta louca está implícita a ideia de que talvez o anormal fosse viver na cidade grande, aceitando-a tal qual ela é.

A mudança de posição que citamos anteriormente também tem como consequência o fato de que narrador e a mademoiselle colocam-se num mesmo plano, animados por suas obsessões, através das quais eles acessam o universo da imaginação e da representação. Reparemos que a fantasia "ser médico" é seriamente representada, primeiro por ela (no fim do poema, ele a compara a uma atriz), com a adesão posterior do narrador. Essa "bizarrerie" possui sua própria lógica, que faz com que se crie um mundo paralelo com suas regras adequadas, mas que fogem do que é considerado racional ou normal. As fotos, por exemplo, apresentadas 
por ela como se fossem "provas" de um passado que justifica as atitudes assumidas no momento do encontro com o narrador, fazem parte, é certo, de elaborações que estão no mundo paralelo que ela criou para si, ainda que algumas tenham sido concretamente realizadas. Essa ambiguidade entre realidade e ficção não possuiria o seu duplo na própria ideia que anima os textos que compõem o livro do poeta francês: a dissolução entre poesia e prosa?

Transpostas para a materialidade linguística, a incorporação do discurso prosaico, a presença dos avanços tecnológicos da modernidade na constituição das referências coesivas do texto, a tematização de situações e de personagens típicas da cidade moderna - a solidão, a loucura, a prostituição e o flâneur - não propõem também o questionamento implicado na ideia do poema em prosa, para o qual já chamamos a atenção no parágrafo anterior?

Para o narrador, coube a tarefa de representar um médico a partir de certos predicativos que a moça, aos poucos, torna conhecidos. Ao colocar em foco a ideia de representação, é possível identificar que uma possível interpretação para a cena retratada no texto de Baudelaire esteja no fato de que o poema seja uma representação da poesia moderna: uma marginalização que torna possível a escrita sobre a complexidade da experiência humana, dialogando com sua realidade e com seu tempo. Do lado do narrador, abandonar-se à ficção e participar da loucura da sua interlocutora são formas de oposição ao vulgar e ao utilitário que ele assume e nos quais ficam implícitas a defesa da imaginação (do contrário, por que teria aceitado o "papel de médico"?) e a revolta contra a opressão vivida na cidade moderna, onde ele também é um pária, junto a outras personagens que desfilam pelo livro de Baudelaire, como o saltimbanco sem público ou o poeta sem auréola.

$\mathrm{O}$ fato de a pergunta feita ao final do poema ("O Créateur! Peut-il exister des monstres aux yeux de Celui-là seul qui sait pourquoi ils existent, comment ils se sont faits et comment ils auraient pu ne pas se faire ?", p. 264, grifo do autor) ${ }^{9}$ permanecer sem resposta parece sinalizar para as duplicidades que permeiam todo o texto. Nesse mesmo parágrafo, o narrador

\footnotetext{
${ }^{9}$ Ó Criador! Podem existir monstros aos olhos Daquele que é o único que sabe por que eles existem, como eles existem e se fizeram e como eles poderiam não ter sido feitos? (p. 265; grifo do autor).
} 
afirma « la vie formille de monstres innocents », p. $264,{ }^{10}$ o que põe em relevo a ambiguidade razão-loucura, no plano temático, e a prosa-poesia, no plano da expressão. Entretanto, o poema não apresenta um fechamento, ou uma moral, mas se volta para uma instância fora do tempo e do espaço (Criador/ Deus), expressando, ironicamente, a mesma surpresa que atinge o leitor ao se deparar com o poema, a começar, como vimos, pelo seu título. E, assim, compartilham narrador e leitor da mesma incerteza diante das várias faces da modernidade que o poema buscou representar.

\section{Considerações Finais}

As duplicidades de sentido sobre as quais os elementos temáticos e expressivos do poema "Mademoiselle Bistouri" estão construídos são evidentes desde o título e parecem encontrar na ideia do poema em prosa uma imagem acabada da proposta de Baudelaire de produzir uma obra condizente com a realidade da sua época (social, econômica, tecnológica e, principalmente, artística), cujos anseios e preferências não estabeleciam mais relações com o que a poesia e arte clássicas podiam oferecer, ainda que o horizonte para onde se voltavam as instâncias formadoras do gosto e da opinião (os jornais, por exemplo) fosse esse.

A escolha dos temas e a forma organizativa do texto sinalizam para uma ideia de poesia que incorpora as condições de produção e de recepção da literatura, trazendo para o seu centro as consequências de um mundo em que homens e mulheres que circulam pelas ruas e pelos bulevares da metrópole estão reduzidos a números e não podem mais ser identificados no meio da multidão.

Ao abalar os paradigmas poéticos com a incorporação de temas e formas considerados não-poéticos, Baudelaire impõe uma revisão dos preceitos que sustentavam os gêneros aperfeiçoando outro, o poema em prosa, cujos reflexos foram sentidos na produção literária posterior e impregnaram seus textos de uma atualidade que nos obriga a ler e discutir seus textos sob as mais variadas perspectivas. Esse trabalho, ao optar pela abordagem de certos traços modernos, buscou cumprir esse caminho, apontando para a importância que a obra de Baudelaire tem na tematização literária da modernidade.

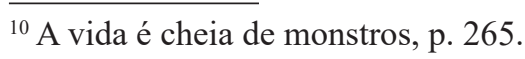




\section{Referências}

BAUDELAIRE, Charles. La reine des facultés. In: Écrits sur l'art. Paris : Librarie Générale Française, 1992. p. 257-261.

BAUDELAIRE, Charles. Mademoiselle Bistouri. In : Pequenos poemas em prosa - Edição bilíngüe. Rio de Janeiro: Record, 2009. Trad.: Gilson Maurity. p. 256-265.

BENJAMIN, Walter. O Flâneur. In: Charles Baudelaire: um lírico no auge do capitalismo. São Paulo: Brasiliense, 1989. Trad.: José Carlos Martins Barbosa e Hemerson Alves Baptista. p. 33-65.

BENJAMIN, Walter. Sobre alguns temas em Baudelaire. In: Charles Baudelaire: um lírico no auge do capitalismo. São Paulo: Brasiliense, 1989. Trad.: José Carlos Martins Barbosa e Hemerson Alves Baptista. p. 103-149.

BERARDINELLI, Alfonso. Baudelaire em prosa. In: AMOROSO, Maria Bethânia (org.). Da poesia à prosa. São Paulo: Cosacnaify, 2007. p. 43-87.

FREUD, Sigmund. Lembrar, repetir, elaborar. Disponível em: https:// psicanalisedownload.files.wordpress.com/2012/08/recordar2.pdf. Acesso em: 10 jun. 2017.

PAZ, Octavio. Os filhos do barro: do romantismo à vanguarda. São Paulo: Cosacnaify, 2013. Trad.: Ari Roitman e Paulina Wacht.

POE, Edgar Allan. O homem da multidão. In: BAUDELAIRE, Charles. O pintor da vida moderna. São Paulo: Autêntica, 2010. Trad.: Tomaz Tadeu. p. 91-102.

THÉLOT, Jerôme. Une collectionneuse du nom de « Bistouri ». Photographie, médecine, folie, prière. In : MURPHY, Steve. Lectures du Spleen de Paris. Rennes: PUR, 2014. p. 219-224.

VAN ZUYLEN, Marina. Monomanie à deux: « Mademoiselle Bistouri » et le dialogue de Baudelaire avec l'insensé. In :Érudit-Études Françaises. Université de Montréal, 2004, volume 40, numéro 2. p. 115-130.

Recebido em: 14 de outubro de 2017. Aprovado em: 06 de fevereiro de 2018. 